\title{
The associations between different sleep patterns and osteoporosis based on the Osteoporosis Self-Assessment Tool for Asians
}

\author{
Shaojun $\mathrm{Wu}^{1} \cdot$ Pengbo Wang ${ }^{1} \cdot$ Xiaofan Guo $^{1} \cdot$ Guozhe Sun ${ }^{1} \cdot$ Ying Zhou $^{1} \cdot$ Zhao $\mathrm{Li}^{1} \cdot$ Hongmei Yang $^{1} \cdot$ Shasha $\mathrm{Yu}^{1}$. \\ Liqiang Zheng ${ }^{2} \cdot$ Yingxian Sun ${ }^{1}$
}

Received: 28 May 2020 / Accepted: 25 September 2020 / Published online: 17 October 2020

(C) The Author(s) 2020

\begin{abstract}
Summary Based on the use of Osteoporosis Self-Assessment Tool for Asians (OSTA) to assess osteoporosis risk, we found that short sleep duration and taking a daytime nap had an increased risk of osteoporosis.

Purpose To explore the associations between different sleep patterns with osteoporosis.

Methods 3659 postmenopausal women (average age of 60 years) were divided into low, middle, and high osteoporosis risk categories based on the Osteoporosis Self-Assessment Tool for Asians (OSTA). After having collected by a standard questionnaire, total and nocturnal sleep duration was collapsed to form categories of $\leq 6 \mathrm{~h},>6 \mathrm{~h}$ and $\leq 7 \mathrm{~h},>7 \mathrm{~h}$ and $\leq 8 \mathrm{~h},>8 \mathrm{~h}$ and $\leq 9 \mathrm{~h}$, $>9 \mathrm{~h}$, and daytime nap duration of $0 \mathrm{~h}$ and $>0 \mathrm{~h}$.

Results As a categorical variable, the total sleep duration of $\leq 6 \mathrm{~h}$ per day (OR $=1.34,95 \% \mathrm{CI} 1.04-1.72)$, nocturnal sleep duration of $\leq 6 \mathrm{~h}$ per night $(\mathrm{OR}=1.65,95 \% \mathrm{CI} 1.24-2.18)$, and taking a daytime nap $(\mathrm{OR}=1.33,95 \% \mathrm{CI} 1.09-$ 1.64) had higher osteoporosis risk after adjustment for covariates. As a continuous variable, after the adjustment for covariates, both longer total $(\mathrm{OR}=0.86,95 \%$ CI $0.78-0.94)$ and nocturnal sleep duration $(\mathrm{OR}=0.83,95 \%$ CI $0.76-$ $0.91)$ had lower risk of osteoporosis risk while taking longer daytime nap (OR $=1.10,95 \%$ CI 1.02-1.19) had higher osteoporosis risk.

Conclusions Postmenopausal women with both short total and nocturnal sleep duration ( $6 \mathrm{~h}$ or less) and taking a daytime nap had increased osteoporosis risk as assessed by OSTA.
\end{abstract}

Keywords Sleep duration · Daytime nap · Osteoporosis · Osteoporosis Self-Assessment Tool for Asians (OSTA)

\author{
Yingxian Sun \\ yxsun@cmu.edu.cn \\ Shaojun Wu \\ sjwu@cmu.edu.cn \\ Pengbo Wang \\ pbwang@cmu.edu.cn \\ Xiaofan Guo \\ guoxiaofan1986@hotmail.com \\ Guozhe Sun \\ gzhsun66@163.com \\ Ying Zhou \\ zhouying8111003@126.com \\ Zhao Li \\ 26890481161@qq.com
}

\author{
Hongmei Yang \\ eileen8222@163.com \\ Shasha Yu \\ yushasha_cmu1h@outlook.com \\ Liqiang Zheng \\ liqiangzheng@126.com \\ 1 Department of Cardiology, The First Hospital of China Medical \\ University, 155 Nanjing North Street, Heping District, \\ Shenyang 110001, Liaoning Province, People's Republic of China \\ 2 Department of Clinical Epidemiology, Library, Shengjing Hospital \\ of China Medical University, Shenyang 110001, Liaoning Province, \\ People's Republic of China
}




\section{Introduction}

Osteoporosis is a systemic bone disease characterized by low bone mineral density (BMD) and micro-architectural deterioration of bone tissue that affects 200 million people worldwide [1]. The commonly unrecognized fracture caused by osteoporosis is often associated with increased mortality, morbidity [2], and health costs [3]. Gender, height, lifestyle patterns, vitamin D intake, and some other potential variables are widely recognized as the risk factors for osteoporosis [4].

Sleep, a fundamental physiological activity and closely related to circadian rhythms, was found to be involved with bone metabolism [5-7]. In addition, a series of epidemiological studies had been performed to explore the association between sleep duration and osteoporosis, of which some [8-10] stated that long sleep duration ( $8 \mathrm{~h}$ or more per day) might be associated with a higher risk of osteoporosis and some [11-13] suggested that those with short sleep duration were more likely to have higher risk of osteoporosis. Interestingly, Swanson et al. [14] reported that between sleep duration and osteoporosis risk in older postmenopausal women, there was no significant association.

Daytime nap, accompanied by many diseases such as obstructive sleep apnea [15] and neuropsychiatric disorders [16], was widely accepted by many Chinese to make up for the short of sleep at night. However, it seemed that taking a daytime nap has been associated with higher risk of mortality [17] while the associations between daytime naps and osteoporosis risk was seldom studied.

Besides the few number of related studies and inconsistent findings, we also noticed that some of these studies were focused on postmenopausal women and used common tools to assess osteoporosis like quantitative ultrasound (QUS); however, it is the tools they used that were not specific for evaluating osteoporosis risk in postmenopausal women. Thus, in the present study, we firstly tried to use the Osteoporosis SelfAssessment Tool for Asians (OSTA), which is specific for Asian postmenopausal women's osteoporosis risk assessment [4], to further explore the association between different sleep patterns and osteoporosis in Chinese postmenopausal women.

\section{Methods and materials}

\section{Study population}

This cross-sectional study was part of the Northeast China Rural Cardiovascular Health Study (NCRCHS) From January 2013 to August 2013, which enrolled 14,016 permanent residents who were older than 35 years of age with $11,956(85.3 \%)$ completed the study. The participants were selected randomly from three regions (Dawa, Zhangwu, and Liaoyang) of Liaoning Province. In the present study, women were included if they had a natural menopause but not a surgical or medically induced menopause for more than 1 year [18]. Then, the participants were excluded if they had missing necessary sleep information, reasons for poor sleep (such as some psychological or neurological disorders), or taken any drugs affecting sleep or bone metabolism during the last 14 days. In the end, a total of 3659 individuals were available for this cross-sectional study.

Written informed consent was obtained from all participants or their proxies if the participants were illiterate, and the study was approved by the Ethics Committee of China Medical University in Shenyang, China.

\section{Osteoporosis assessment}

The Osteoporosis Self-Assessment Tool for Asians (OSTA) was developed by Koh et al. [4], an index which was initially generated by recruiting Asian postmenopausal women in eight Asian countries or regions. After having evaluated the potential risk factors for osteoporosis and validated in Japan, the OSTA index equation, $0.2 \times$ [body weight $(\mathrm{kg})-$ age (years)], proved to perform well for identifying postmenopausal women with osteoporosis. In addition, two studies $[19,20]$ reported superior combined sensitivity and specificity with the OSTA index, compared with the US Preventive Services Task Force (USPSTF). Another study [21] indicated that to select men older than 70 years for osteoporosis screening, the OSTA index performed even better than the more complex Fracture Risk Assessment Tool (FRAX). Therefore, in our study, we calculated the osteoporosis risk index using the OSTA index equation and classified the participants into low $(<-4)$, middle $(-4$ to -1$)$, and high $(>-1)$ osteoporosis risk categories according to the recommended criterion.

\section{Sleep patterns}

Information on individual sleep patterns including total sleep duration, nocturnal sleep duration, and daytime nap duration was collected by a standard questionnaire. According to total and nocturnal sleep duration, the participants were classified into five groups: $\leq 6 \mathrm{~h},>6 \mathrm{~h}$ and $\leq 7 \mathrm{~h},>7 \mathrm{~h}$ and $\leq 8 \mathrm{~h},>8 \mathrm{~h}$ and $\leq 9 \mathrm{~h}$, and $>9 \mathrm{~h}$, of which $>7 \mathrm{~h}$ and $\leq 8 \mathrm{~h}$ was selected as the reference category because it was recommended for adults [22]. Two groups of $0 \mathrm{~h}$ and $>0 \mathrm{~h}$ were set up at the same time by daytime nap duration and the former was the reference category.

\section{Other measurements and definitions}

In the present study, demographics and menopause status were collected at the research visit by experienced cardiologists and trained nurses who used a standard questionnaire to 
conduct a face-to-face interview. Waist circumference and height were measured both to the nearest $0.1 \mathrm{~cm}$, weight was measured to the nearest $0.1 \mathrm{~kg}$, then the waist to height ratio (WHtR) was calculated as waist circumference $(\mathrm{cm})$ divided by height $(\mathrm{cm})$, and BMI was calculated as the individual's weight $(\mathrm{kg})$ divided by the square of the height $\left(\mathrm{m}^{2}\right)$. Fasting blood samples were obtained in the morning after more than $8 \mathrm{~h}$ of fasting for all participants. Blood samples were collected from an antecubital vein into vacutainer tubes containing EDTA. Serum was subsequently isolated from whole blood and all serum samples were frozen at $-20^{\circ} \mathrm{C}$ for testing at a central, certified laboratory. Total cholesterol (TC), triglycerides (TG), high-density lipid cholesterol (HDLC), and low-density lipid cholesterol (LDL-C) were measured with an auto-analyzer. All data were recorded by standard methods and all laboratory equipment was calibrated.

All participants were asked about the current status of smoking, drinking, taking estrogen, and the history of hyperthyroidism. Three times $(45 \mathrm{~min} /$ time $)$ a week for at least 3 months exercise was considered a regular physical activity. Educational level was divided into three levels: low (primary school or less), middle (middle school and high school), and high (college or more). Hypertension was defined as a systolic blood pressure (SBP) $\geq 140 \mathrm{mmHg}$, a diastolic blood pressure (DBP) $\geq 90 \mathrm{mmHg}$, and/or receiving treatment for hypertension; diabetes mellitus was diagnosed as a fasting blood glucose $(\mathrm{FBG}) \geq 7 \mathrm{mmol} / \mathrm{L}$ and/or receiving anti-diabetic treatment.

\section{Statistical analysis}

Baseline characteristics were presented as mean \pm standard deviation or frequencies with percentages, compared by $P$ values from a trend test. The mean duration of different sleep patterns among osteoporosis risk categories were calculated and presented; $P$ values from a trend test was used to evaluate the associations between them. To test the associations between osteoporosis risk and total sleep duration, nocturnal sleep duration, or daytime nap duration categories, two logistic regression models were established. Model A was unadjusted and the potential risk factors for osteoporosis were further adjusted in Model B. The odds ratios (ORs) and 95\% confidence intervals (CIs) were shown.

SPSS 25.0 for Windows (SPSS Inc., Chicago, USA) was used for analysis, $P<0.05$ was considered significant.

\section{Results}

Baseline characteristics of the 3659 postmenopausal women at the average age of 60 years across osteoporosis risk groups are presented in Table 1. The low osteoporosis risk occurred in 2329 (63.7\%) participants, middle osteoporosis risk in 1007
(27.5\%), and high osteoporosis risk in $323(8.8 \%)$. The mean age $(P<0.001)$ and HDL-C $(P<0.001)$ increased while the mean BMI $(P<0.001)$, WHtR $(P<0.001)$, TG $(P<0.001)$, and LDL-C $(P=0.001)$ decreased across the osteoporosis risk categories. Hypertension, currently smoking, currently drinking, and regular physical activity were more often found in individuals with high osteoporosis risk $(65.9 \%, 33.7 \%, 5.6 \%$, and $30.0 \%$, respectively) while those who were diagnosed with diabetes mellitus were prone to low osteoporosis risk. Furthermore, we found most of the participants were Han nationality $(P=0.001)$ with a low level of education $(P<$ $0.001)$. When it comes to currently taking estrogen $(P=$ $0.821)$, history of hyperthyroidism $(P=0.914)$, and TC $(P=$ $0.359)$, there were no significant associations with the osteoporosis risk. Last but not least, those who had short total $(P=$ $0.001)$ and nocturnal $(P<0.001)$ sleep duration $(6 \mathrm{~h}$ or less $)$ and taking a daytime nap $(P<0.001)$ were prone to high osteoporosis risk.

The mean duration of different sleep patterns by osteoporosis risk category is presented in Fig. 1. As a result, the mean duration of nocturnal sleep duration decreased significantly with advancing osteoporosis risk category from the highest of $6.64 \mathrm{~h}$ to the lowest of $6.26 \mathrm{~h}(P<0.001)$. The opposite trend was observed in daytime nap duration with the mean value increased from the lowest of $0.28 \mathrm{~h}$ to the highest of $0.45 \mathrm{~h}(P<0.001)$. Individuals with low osteoporosis risk were more likely to have the longest total sleep duration while those in middle osteoporosis risk category had the shortest $(P<0.001)$.

Unadjusted and multivariable adjusted ORs and 95\% CIs for osteoporosis risk are presented in Table 2 according to baseline total sleep duration, nocturnal sleep duration, and daytime nap duration, expressed as categorical variable respectively. A 1.34-fold risk of osteoporosis in Model A $(\mathrm{OR}=1.34,95 \% \mathrm{CI} 1.13-1.60)$ and a 1.35 -fold risk of osteoporosis in Model B (OR $=1.35,95 \%$ CI 1.04-1.72) were detected in total sleep duration of $6 \mathrm{~h}$ or less per day, compared with total sleep duration of $>7 \mathrm{~h}$ and $\leq 8 \mathrm{~h}$. Nocturnal sleep duration of $\leq 6 \mathrm{~h}$ was also more likely to have higher osteoporosis risk, compared with that of $>7 \mathrm{~h}$ and $\leq 8 \mathrm{~h}$ both in Model A (OR $=1.55,95 \%$ CI 1.28-1.89) and Model B (OR = $1.65,95 \%$ CI 1.24-2.18). Participants taking a nap (daytime nap duration $>0 \mathrm{~h}$ ) were prone to higher osteoporosis risk $(\mathrm{OR}=1.58,95 \%$ CI $1.37-1.81)$, compared with those who had no daytime nap (daytime nap duration $=0 \mathrm{~h}$ ), and after adjustment for covariates, this trend persisted $(\mathrm{OR}=1.33$, 95\% CI 1.09-1.64). There were no significant associations of other total sleep duration, nocturnal sleep duration, and daytime nap duration categories with osteoporosis risk when compared with the corresponding reference category.

Unadjusted and multivariable adjusted ORs and 95\% CIs for osteoporosis risk are also presented in Table 3 according to different sleep patterns, but expressed as continuous variable. 
Table 1 Baseline characteristics of study participants across osteoporosis risk categories

\begin{tabular}{|c|c|c|c|c|c|}
\hline \multirow[t]{2}{*}{ Characteristics } & \multirow[t]{2}{*}{ Total $(n=3659)$} & \multicolumn{3}{|l|}{ Osteoporosis risk } & \multirow[t]{2}{*}{$P$ for trend } \\
\hline & & Low $(n=2329)$ & Middle $(n=1007)$ & $\operatorname{High}(n=323)$ & \\
\hline Age, years & $60 \pm 8$ & $56 \pm 6$ & $64 \pm 6$ & $73 \pm 6$ & $<0.001$ \\
\hline Age at menopause, years & $49 \pm 5$ & $49 \pm 5$ & $49 \pm 5$ & $48 \pm 4$ & 0.029 \\
\hline BMI, $\mathrm{kg} / \mathrm{m}^{2}$ & $24.83 \pm 3.86$ & $26.33 \pm 3.51$ & $22.71 \pm 2.84$ & $20.69 \pm 2.86$ & $<0.001$ \\
\hline WHtR & $0.53 \pm 0.07$ & $0.55 \pm 0.06$ & $0.51 \pm 0.06$ & $0.50 \pm 0.07$ & $<0.001$ \\
\hline \multicolumn{6}{|l|}{ Education level, $n(\%)$} \\
\hline Low & $2647(72.3)$ & $1532(65.8)$ & $837(83.1)$ & $278(86)$ & \multirow[t]{3}{*}{$<0.001$} \\
\hline Middle & $957(26.1)$ & $758(32.5)$ & $165(16.4)$ & $44(13.6)$ & \\
\hline High & $32(0.87)$ & $31(1.33)$ & $1(0.09)$ & $0(0.00)$ & \\
\hline \multicolumn{5}{|l|}{ Nation, $n(\%)$} & \multirow[t]{3}{*}{0.001} \\
\hline Han & $3487(95.3)$ & $2198(94.4)$ & $976(96.9)$ & $313(96.9)$ & \\
\hline Other & $172(4.7)$ & $131(5.6)$ & $31(3.1)$ & $10(3.1)$ & \\
\hline \multicolumn{6}{|l|}{ Currently smoking, $n(\%)$} \\
\hline Yes & $739(20.2)$ & $357(15.3)$ & $273(27.1)$ & $109(33.7)$ & \multirow[t]{2}{*}{$<0.001$} \\
\hline No & $2920(79.8)$ & $1972(84.7)$ & $734(72.9)$ & $214(66.3)$ & \\
\hline \multicolumn{6}{|l|}{ Currently drinking, $n(\%)$} \\
\hline Yes & $107(2.9)$ & $54(2.3)$ & $35(3.5)$ & $18(5.6)$ & \multirow[t]{2}{*}{0.001} \\
\hline No & $3552(97.1)$ & 2275 (97.7) & $972(96.5)$ & $305(94.4)$ & \\
\hline \multicolumn{6}{|c|}{ Currently taking estrogen, $n(\%)$} \\
\hline Yes & $32(0.9)$ & $20(0.9)$ & $10(1.0)$ & $2(0.6)$ & \multirow[t]{2}{*}{0.821} \\
\hline No & $2792(76.3)$ & $1836(78.8)$ & $760(75.5)$ & $196(60.7)$ & \\
\hline \multicolumn{6}{|c|}{ Regular physical activity, $n(\%)$} \\
\hline Yes & 973 (26.6) & $596(25.6)$ & $280(27.8)$ & $97(30.0)$ & \multirow[t]{2}{*}{0.048} \\
\hline No & $2686(73.4)$ & $1733(74.4)$ & $727(72.2)$ & $226(70.0)$ & \\
\hline \multicolumn{6}{|l|}{ Hypertension, $n(\%)$} \\
\hline Yes & $2131(58.3)$ & $1339(57.5)$ & $579(57.6)$ & $213(65.9)$ & \multirow[t]{2}{*}{0.028} \\
\hline No & $1527(41.7)$ & $990(42.5)$ & $427(42.4)$ & $110(34.1)$ & \\
\hline \multicolumn{5}{|l|}{ Diabetes mellitus, $n(\%)$} & \multirow[t]{3}{*}{0.004} \\
\hline Yes & $491(13.5)$ & $338(14.6)$ & $123(12.3)$ & $30(9.3)$ & \\
\hline No & $3148(86.5)$ & $1981(85.4)$ & $875(87.7)$ & $292(90.7)$ & \\
\hline History of hyperthyroidisn & & & & & \\
\hline Yes & $96(2.6)$ & $61(2.6)$ & $30(3.0)$ & $5(1.5)$ & 0.914 \\
\hline No & $2892(79.0)$ & $1910(82.0)$ & $779(77.4)$ & $203(62.8)$ & \\
\hline Total sleep duration, $\mathrm{h}$ & & & & & \\
\hline$\leq 6, n(\%)$ & $1456(39.8)$ & $868(37.3)$ & $444(44.1)$ & $144(44.6)$ & 0.001 \\
\hline$>6$ and $\leq 7, n(\%)$ & 709 (19.4) & $467(20.1)$ & $197(19.6)$ & $45(13.9)$ & \\
\hline$>7$ and $\leq 8, n(\%)$ & $866(23.7)$ & $576(24.7)$ & $225(22.3)$ & $65(20.1)$ & \\
\hline$>8$ and $\leq 9, n(\%)$ & $410(11.2)$ & $270(11.6)$ & $95(9.4)$ & $45(13.9)$ & \\
\hline$>9, n(\%)$ & $199(5.4)$ & $135(5.8)$ & $42(4.2)$ & $22(6.8)$ & \\
\hline Nocturnal sleep duration, & & & & & \\
\hline$\leq 6, n(\%)$ & $981(26.8)$ & $554(23.8)$ & $310(30.8)$ & $117(36.2)$ & $<0.001$ \\
\hline$>6$ and $\leq 7, n(\%)$ & $799(21.8)$ & $505(21.7)$ & $236(23.4)$ & $58(18.0)$ & \\
\hline$>7$ and $\leq 8, n(\%)$ & $704(19.2)$ & $466(20.0)$ & $193(19.2)$ & 45 (13.9) & \\
\hline$>8$ and $\leq 9, n(\%)$ & $934(25.5)$ & $643(27.6)$ & $211(21.0)$ & $80(24.8)$ & \\
\hline$>9, n(\%)$ & $232(6.3)$ & $155(6.7)$ & $54(5.4)$ & $23(7.1)$ & \\
\hline Daytime nap duration, $\mathrm{h}$ & & & & & \\
\hline$=0, n(\%)$ & $2487(68.0)$ & $1661(71.3)$ & $653(64.8)$ & $173(53.6)$ & $<0.001$ \\
\hline$>0, n(\%)$ & $1158(31.6)$ & $659(28.3)$ & $351(34.9)$ & $148(45.8)$ & \\
\hline $\mathrm{TG}, \mathrm{mmol} / \mathrm{L}$ & $1.82 \pm 1.46$ & $1.93 \pm 1.59$ & $1.64 \pm 1.19$ & $1.55 \pm 1.13$ & $<0.001$ \\
\hline $\mathrm{TC}, \mathrm{mmol} / \mathrm{L}$ & $5.60 \pm 1.12$ & $5.61 \pm 1.15$ & $5.61 \pm 1.09$ & $5.54 \pm 0.98$ & 0.359 \\
\hline LDL-C, $\mathrm{mmol} / \mathrm{L}$ & $3.18 \pm 0.86$ & $3.21 \pm 0.33$ & $3.15 \pm 0.85$ & $3.05 \pm 0.78$ & 0.001 \\
\hline $\mathrm{HDL}-\mathrm{C}, \mathrm{mmol} / \mathrm{L}$ & $1.42 \pm 0.35$ & $1.38 \pm 0.33$ & $1.46 \pm 0.37$ & $1.54 \pm 0.40$ & $<0.001$ \\
\hline
\end{tabular}

$B M I$, body mass index; $W H t R$, waist to height ratio; $T G$, triacylglycerol; $T C$, cholesterol; $L D L-C$, low-density lipoprotein cholesterol; $H D L-C$, highdensity lipoprotein cholesterol

Both in Model A (per 1 SD: OR $=0.87,95 \%$ CI 0.82-0.93) and Model B (per 1 SD: OR $=0.86,95 \%$ CI 0.78-0.94), longer total sleep duration was significantly associated with a lower risk of osteoporosis risk. In addition, getting more nocturnal sleep was also more likely to have lower osteoporosis risk whether in Model A (per 1 SD: OR $=0.82,95 \%$ CI $0.76-$ 0.87 ) or Model B (per 1 SD: OR $=0.83,95 \%$ CI 0.76-0.91). Interestingly, individuals taking longer daytime nap were prone to higher osteoporosis risk (per $1 \mathrm{SD}$ : $\mathrm{OR}=1.16,95 \%$ CI 1.09-1.24), and the same trend was observed even after 
adjustment for covariates (per $1 \mathrm{SD}: \mathrm{OR}=1.10,95 \%$ CI $1.02-$ 1.19).

\section{Discussion}

In the present cross-sectional study, we found a significant association between different sleep patterns and osteoporosis even after adjustment for the potential confounding factors based on the Osteoporosis Self-Assessment Tool for Asian postmenopausal women to assess osteoporosis risk. Both total sleep duration and nocturnal sleep duration of $6 \mathrm{~h}$ or less per day were related to an increased risk of osteoporosis when compared with total sleep duration or nocturnal sleep duration of $>7 \mathrm{~h}$ and $\leq 8 \mathrm{~h}$, and compared with those taking no daytime nap (daytime nap duration $=0 \mathrm{~h}$ ), individuals taking a nap (daytime nap duration $>0 \mathrm{~h}$ ) were significantly associated with an elevated osteoporosis risk.

Inadequate sleep duration $(<6 \mathrm{~h})$ was associated with osteoporosis. A latest research of 11,084 women in America reported that short nocturnal sleep duration was associated with a higher risk of osteoporosis when comparing across the different sleep duration categories [11]. Another Chinese study also indicated that an increased risk of osteoporosis in women with nocturnal sleep duration of $7 \mathrm{~h}$ or less per night was detected [12]. In addition, Fu et al. [13] found that compared with those who slept $8 \mathrm{~h}$, women at the age of 18 to 80 years who slept $6 \mathrm{~h}$ or less per night had a significantly lower level of BMD and a high level of osteoporosis risk. These three cross-sectional studies support our findings that short sleep duration may be associated with an increased risk of osteoporosis.

On the contrary, long sleep was also associated with osteoporosis. A Japanese study that included 19,321 individuals older than 50 years stated that self-reported sleep duration of more than $8 \mathrm{~h}$ have higher odds of osteoporosis [8]. Another Chinese sample that included 31,769 participants (aged 4586 years) also found that long sleeping $\geq 8 \mathrm{~h}$ was more likely to have higher osteoporosis risk [9]. The present work did not agree with findings of the two cross-sectional studies, which may be due to the fact that we focused on postmenopausal women, but the Japanese study included more than $50 \%$ of men and few participants in the Chinese sample (men for $5.0 \%$, women for $4.9 \%$ ) reported sleeping $7 \mathrm{~h}$ or less hours per night.

To our knowledge, even though the underlying mechanism between sleep duration and osteoporosis risk is not fully understood, the decrease in melatonin [23] and growth hormone (GH) [24], and the increase in glucocorticoids [25] and inflammatory cytokines [26, 27] resulted from inadequate sleep which could play an important role. First, a randomized controlled trial (RCT) [28] found that treatment with melatonin increased BMD while the same result was observed in an animal study [29], another RCT [30] indicated that GH treatment in postmenopausal osteoporosis reduced the fracture incidence by $28 \%$ during the 10 years follow-up, and Tritos' analysis [31] also suggested that $\mathrm{GH}$ treatment was associated with decreased fracture risk in adults. Then, two studies [32, 33] presented that elevated circulating glucocorticoids reduced the osteoblast function while the two other studies $[34,35]$ demonstrated that increased circulating inflammatory cytokines had the same effect. To sum up, inadequate sleep could disrupt endocrine and metabolic function, leading to the decreased bone mineral density and osteoblast formation, thus resulting in an increased osteoporosis risk.

It was also a noteworthy finding that compared with those taking no daytime nap, individuals taking a nap were significantly associated with an elevated risk of osteoporosis in the present study. Similar result was found in previous studies of Stone et al. [36] and Chen et al. [37]. One potential explanation is that taking a daytime nap is trying to compensate for poor nocturnal sleep [37]. As we demonstrated in Table 3, longer daytime nap duration was significantly associated with a greater risk of osteoporosis with an odds ratio of 1.10 per standard deviation while longer nocturnal sleep duration was significantly associated with a lower risk of osteoporosis with an odds ratio of 0.83 per standard deviation in adjusted analyses. Another explanation could be the significant decrease in 6-sulfatoxymelatonin level [38] and urinary melatonin level [39] during daytime sleep among women.
Fig. 1 The mean durations of different sleep patterns by osteoporosis risk categories

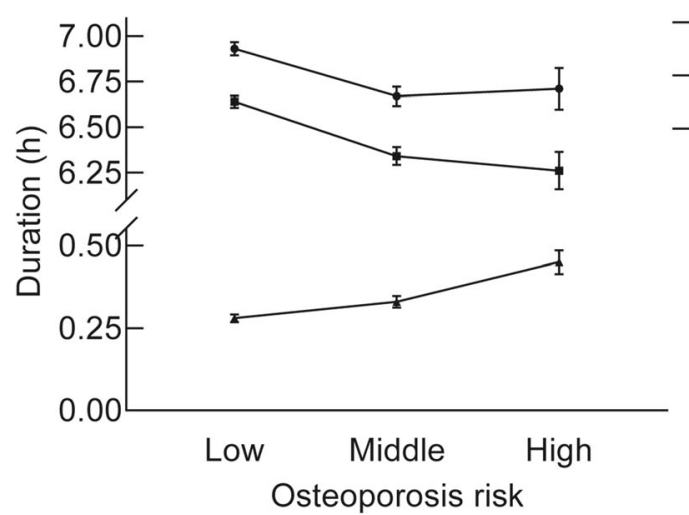

$\rightarrow$ Total sleep duration

$\rightarrow$ Nocturnal sleep duration

$\rightarrow$ Daytime nap duration 
Table 2 Logistic regression models for osteoporosis risk and different sleep patterns (as categorical variable)

\begin{tabular}{|c|c|c|c|c|c|}
\hline \multirow[t]{2}{*}{ Variables } & \multirow[t]{2}{*}{ Number } & \multicolumn{2}{|l|}{ Model $A^{\mathrm{a}}$} & \multicolumn{2}{|l|}{ Model B ${ }^{\mathrm{b}}$} \\
\hline & & OR $(95 \% \mathrm{CI})$ & $P$ value & OR $(95 \% \mathrm{CI})$ & $P$ value \\
\hline \multicolumn{6}{|l|}{ Total sleep duration, $\mathrm{h}$} \\
\hline$\leq 6$ & 1456 & $1.34(1.13,1.60)$ & 0.001 & $1.35(1.04,1.72)$ & 0.021 \\
\hline$>6$ and $\leq 7$ & 709 & $1.01(0.82,1.24)$ & 0.933 & $0.89(0.67,1.21)$ & 0.470 \\
\hline$>7$ and $\leq 8$ & 866 & 1 (reference) & - & 1 (reference) & - \\
\hline$>8$ and $\leq 9$ & 410 & $1.08(0.85,1.38)$ & 0.528 & $1.04(0.73,1.47)$ & 0.828 \\
\hline$>9$ & 199 & $0.99(0.72,1.38)$ & 0.992 & $0.84(0.51,1.36)$ & 0.485 \\
\hline Test of parallel lines & - & - & 0.111 & - & 0.191 \\
\hline \multicolumn{6}{|c|}{ Nocturnal sleep duration, $\mathrm{h}$} \\
\hline$\leq 6$ & 981 & $1.55(1.28,1.89)$ & $<0.001$ & $1.65(1.24,2.18)$ & 0.001 \\
\hline$>6$ and $\leq 7$ & 799 & $1.14(0.92,1.40)$ & 0.231 & $1.29(0.96,1.74)$ & 0.094 \\
\hline$>7$ and $\leq 8$ & 704 & 1 (reference) & - & 1 (reference) & - \\
\hline$>8$ and $\leq 9$ & 934 & $0.92(0.75,1.14)$ & 0.460 & $1.13(0.84,1.58)$ & 0.429 \\
\hline$>9$ & 232 & $1.03(0.75,1.39)$ & 0.865 & $1.13(0.72,1.77)$ & 0.590 \\
\hline Test of parallel lines & - & - & 0.121 & - & 0.187 \\
\hline \multicolumn{6}{|l|}{ Daytime nap duration, $\mathrm{h}$} \\
\hline$=0$ & 2487 & 1 (reference) & - & 1 (reference) & - \\
\hline$>0$ & 1158 & $1.58(1.37,1.81)$ & $<0.001$ & $1.33(1.09,1.64)$ & 0.006 \\
\hline Test of parallel lines & - & - & 0.145 & - & 0.137 \\
\hline
\end{tabular}

${ }^{\text {a }}$ Model A was unadjusted

${ }^{\mathrm{b}}$ Model B was adjusted for age at menopause, BMI, WHtR, education level, nation, currently smoking, currently drinking, currently taking estrogen, physical activity, hypertension, diabetes mellitus, history of hyperthyroidism, TG, TC, LDL-C, and HDL-C
There were several strengths in the present study. First, sleep duration was divided into five categories, which allowed us to evaluate the association between total or nocturnal sleep duration and osteoporosis more thoroughly. Second, a number of potential risk factors for osteoporosis were included in the analysis, such as age at menopause, smoking, and drinking. Third, we explored the associations between osteoporosis and different sleep patterns by firstly using the OSTA index which
Table 3 Logistic regression models for osteoporosis risk and different sleep patterns (as continuous variable)

\begin{tabular}{|c|c|c|c|c|c|}
\hline \multirow[t]{2}{*}{ Variables } & \multirow[t]{2}{*}{ Mean \pm SD } & \multicolumn{2}{|l|}{ Model $A^{a}$} & \multicolumn{2}{|l|}{ Model B } \\
\hline & & OR $(95 \% \mathrm{CI})$ & $P$ value & OR $(95 \% \mathrm{CI})$ & $P$ value \\
\hline \multicolumn{6}{|l|}{ Total sleep duration } \\
\hline Per $1 \mathrm{SD}$ & $0.000 \pm 1.000$ & $0.87(0.82,0.93)$ & $<0.001$ & $0.86(0.78,0.94)$ & 0.001 \\
\hline Test of parallel lines & - & - & 0.232 & - & 0.145 \\
\hline \multicolumn{6}{|l|}{ Nocturnal sleep duration } \\
\hline Per 1 SD & $-0.001 \pm 1.000$ & $0.82(0.76,0.87)$ & $<0.001$ & $0.83(0.76,0.91)$ & $<0.001$ \\
\hline Test of parallel lines & - & - & 0.618 & - & 0.148 \\
\hline \multicolumn{6}{|l|}{ Daytime nap duration } \\
\hline Per 1 SD & $-0.002 \pm 0.997$ & $1.16(1.09,1.24)$ & $<0.001$ & $1.10(1.02,1.19)$ & 0.017 \\
\hline Test of parallel lines & - & - & 0.155 & - & 0.291 \\
\hline
\end{tabular}

$S D$, standard deviation

${ }^{\mathrm{a}}$ Model A was unadjusted

${ }^{\mathrm{b}}$ Model B was adjusted for age at menopause, BMI, WHtR, education level, nation, currently smoking, currently drinking, currently taking estrogen, physical activity, hypertension, diabetes mellitus, history of hyperthyroidism, TG, TC, LDL-C, and HDL-C 
was developed specifically for Asian postmenopausal women to assess osteoporosis risk.

However, some limitations also exist in the present study. First, this is a cross-sectional study; therefore, although short total sleep duration, short nocturnal sleep duration, and taking a daytime napping were associated with higher osteoporosis risk, we could not deduce the causal associations between them. Second, data about some factors affecting bone metabolism, such as previous fragility fractures for the women, history of rheumatoid arthritis, and family history of hip fractures, calcium and vitamin D intakes were not collected in the present study. Third, information on sleep patterns were collected by the use of self-reported measures like many studies, which might cause potential recall bias.

In conclusion, the present study found that significant associations existed between different sleep patterns and osteoporosis risk. Both total sleep duration and nocturnal sleep duration of $6 \mathrm{~h}$ or less per day were related to an increased risk of osteoporosis when compared with total sleep duration or nocturnal sleep duration of $>7 \mathrm{~h}$ and $\leq 8 \mathrm{~h}$, and individuals taking a nap were significantly associated with an elevated risk of osteoporosis compared with those taking no daytime nap. However, further researches related to the topic including more complete and objective information are needed to be performed.

Acknowledgments We thank cardiologists and staffs from CDCs of Fuxin City, Panjin City, and Liaoyang City in Liaoning Province who work hard to ensure the reliability and accuracy of data.

Authors' contributions Yingxian Sun directed the design of study. Xiaofan Guo, Guozhe Sun, Ying Zhou, Zhao Li, Hongmei Yang, Shasha $\mathrm{Yu}$, and Liqiang Zheng were responsible for conducting the study. Shaojun $\mathrm{Wu}$ and Pengbo Wang analyzed the data. Shaojun $\mathrm{Wu}$ wrote the manuscript. All authors read and approved the final manuscript.

Funding This study was supported by The National Key Research and Development Program of China (Project Grant \#2017YFC1307600), The National Natural Science Foundation of China (Project Grant \#81800361), and Liaoning Science and Technology Project, research and demonstration of hypertension diagnosis and treatment and optimization of process management in Liaoning Province community (Project Grant \#2017107001).

\section{Compliance with ethical standards}

Ethical approval This study was conducted according to the guidelines laid down in the Declaration of Helsinki and all procedures involving research study participants were approved by the Ethics Committee of China Medical University (Shenyang, China, ethical approved project identification code: AF-SOP-07-1, 0-01).

Conflict of interest The authors declare that they have no conflict of interest.

Consent to participate Written informed consent was obtained from all subjects.
Consent for publication The authors certify that they have participated sufficiently in the work to take public responsibility for the appropriateness of the experimental design and method, and the collection, analysis, and interpretation of the dada. This manuscript has been published in whole or in part, nor is it being considered for publication elsewhere.

Open Access This article is licensed under a Creative Commons Attribution 4.0 International License, which permits use, sharing, adaptation, distribution and reproduction in any medium or format, as long as you give appropriate credit to the original author(s) and the source, provide a link to the Creative Commons licence, and indicate if changes were made. The images or other third party material in this article are included in the article's Creative Commons licence, unless indicated otherwise in a credit line to the material. If material is not included in the article's Creative Commons licence and your intended use is not permitted by statutory regulation or exceeds the permitted use, you will need to obtain permission directly from the copyright holder. To view a copy of this licence, visit http://creativecommons.org/licenses/by/4.0/.

\section{References}

1. Avenell A, Bolland MJ, Grey A, Reid IR (2017) Further major uncorrected errors in National Osteoporosis Foundation metaanalyses of calcium and vitamin D supplementation in fracture prevention. Osteoporosis Int 28(2):733-734. https://doi.org/10. 1007/s00198-016-3765-6

2. Lane NE (2006) Epidemiology, etiology, and diagnosis of osteoporosis. Am J Obstet Gynecol 194(2 Suppl):S3-S11. https://doi.org/ 10.1016/j.ajog.2005.08.047

3. Hauselmann HJ, Rizzoli R (2003) A comprehensive review of treatments for postmenopausal osteoporosis. Osteoporos Int 14(1):212. https://doi.org/10.1007/s00198-002-1301-3

4. Koh LKH, Ben Sedrine W, Torralba TP, Kung A, Fujiwara S, Chan SP, Huang QR, Rajatanavin R, Tsai KS, Park HM, Reginster JY, Grp OR (2001) A simple tool to identify Asian women at increased risk of osteoporosis. Osteoporosis Int 12(8):699-705. https://doi. org $/ 10.1007 / \mathrm{s} 001980170070$

5. Swanson CM, Kohrt WM, Buxton OM, Everson CA, Wright KP Jr, Orwoll ES, Shea SA (2018) The importance of the circadian system \& sleep for bone health. Metabolism 84:28-43. https://doi.org/10. 1016/j.metabol.2017.12.002

6. Tian Li SJ, Lu C, Yang W, Yang Z, Hu W, Xin Z, Yang Y (2019) Melatonin: another avenue for treating osteoporosis? J Pineal Res 66(2):e12548

7. Redmond J, Fulford AJ, Jarjou L, Zhou B, Prentice A, Schoenmakers I (2016) Diurnal rhythms of bone turnover markers in three ethnic groups. J Clin Endocrinol Metab 101(8):3222-3230. https://doi.org/10.1210/jc.2016-1183

8. Kobayashi D, Takahashi O, Deshpande GA, Shimbo T, Fukui T (2012) Association between osteoporosis and sleep duration in healthy middle-aged and elderly adults: a large-scale, crosssectional study in Japan. Sleep Breath 16(2):579-583. https://doi. org/10.1007/s11325-011-0545-6

9. Tian Y, Shen L, Wu J, Xu G, Yang S, Song L, Zhang Y, Mandiwa C, Yang H, Liang Y, Wang Y (2015) Sleep duration and timing in relation to osteoporosis in an elderly Chinese population: a crosssectional analysis in the Dongfeng-Tongii cohort study. Osteoporos Int 26(11):2641-2648. https://doi.org/10.1007/s00198-015-3172-4

10. Moradi S, Shab-bidar S, Alizadeh S, Djafarian K (2017) Association between sleep duration and osteoporosis risk in middle-aged and elderly women: a systematic review and metaanalysis of observational studies. Metabolism 69:199-206. https://doi.org/10.1016/j.metabol.2017.01.027 
11. Ochs-Balcom HM, Hovey KM, Andrews C, Cauley JA, Hale L, Li WJ, Bea JW, Sarto GE, Stefanick ML, Stone KL, Watts NB, Zaslavsky O, Wactawski-Wende J (2020) Short sleep is associated with low bone mineral density and osteoporosis in the Women's Health Initiative. J Bone Miner Res 35(2):261-268. https://doi.org/10.1002/jbmr.3879

12. Wang K, Wu Y, Yang Y, Chen J, Zhang DY, Hu YX, Liu ZJ, Xu J, Shen QX, Zhang NY, Mao XD, Liu C (2015) The associations of bedtime, nocturnal, and daytime sleep duration with bone mineral density in pre- and post-menopausal women. Endocrine 49(2):538 548. https://doi.org/10.1007/s12020-014-0493-6

13. Fu XH, Zhao XY, Lu H, Jiang F, Ma XG, Zhu SK (2011) Association between sleep duration and bone mineral density in Chinese women. Bone 49(5):1062-1066. https://doi.org/10.1016/ j.bone.2011.08.008

14. Swanson CM, Blatchford PJ, Orwoll ES, Cauley JA, LeBlanc ES, Fink HA, Wright KP, Wierman ME, Kohrt WM, Stone KL, Cummings SR, Yaffe K, Bauer DC, Black DM, Cawthon PM, Lane N, McCulloch C, Schwartz A, Tranah G, Evans D, Benard R, Blackwell T, Concepcion L, Ewing S, Harrison SL, Kriesel D, Parimi N, Peters K, Schambach C, Ziamo J, SOF SOF (2019) Association between objective sleep duration and bone mineral density in older postmenopausal women from the Study of Osteoporotic Fractures (SOF). Osteoporosis Int 30(10):20872098. https://doi.org/10.1007/s00198-019-05007-5

15. Lavie P (2002) Incidence of sleep apnea in a presumably healthy working population: a significant relationship with excessive daytime sleepiness. Sleep 25(4):312-318

16. Foley D, Monjan A, Masaki K, Ross W, Havlik R, White L, Launer L (2001) Daytime sleepiness is associated with 3-year incident dementia and cognitive decline in older Japanese-American men. J Am Geriatr Soc 49(12):1628-1632. https://doi.org/10.1046/j.1532-5415.2001.t011-49271.x

17. Hays JC, Blazer DG, Foley DJ (1996) Risk of napping: excessive daytime sleepiness and mortality in an older community population. J Am Geriatr Soc 44(6):693-698. https://doi.org/10.1111/j.15325415.1996.tb01834.x

18. Research on the menopause (1981) World Health Organ Tech Rep Ser 670:1-120

19. Crandall CJ, Larson J, Gourlay ML, Donaldson MG, LaCroix A, Cauley JA, Wactawski-Wende J, Gass ML, Robbins JA, Watts NB, Ensrud KE (2014) Osteoporosis screening in postmenopausal women 50 to 64 years old: comparison of US Preventive Services Task Force Strategy and two traditional strategies in the Women's Health Initiative. J Bone Miner Res 29(7):1661-1666. https:/doi. org/10.1002/jbmr.2174

20. Leslie WD, Lix LM, Johansson H, Oden A, McCloskey E, Kanis JA, Program MBD (2013) Selection of women aged 50-64 yr for bone density measurement. J Clin Densitom 16(4):570-578. https:// doi.org/10.1016/j.jocd.2013.01.004

21. Diem SJ, Peters KW, Gourlay ML, Schousboe JT, Taylor BC, Orwoll ES, Cauley JA, Langsetmo L, Crandall CJ, Ensrud KE, Osteoporotic Fractures in Men Research G (2017) Screening for osteoporosis in older men: operating characteristics of proposed strategies for selecting men for BMD testing. J Gen Intern Med 32(11):1235-1241. https://doi.org/10.1007/s11606-017-4153-4

22. Explore sleep deprivation and deficiency: how much sleep is enough? (2012). National Heart, Lung, and Blood Institute http:// www.nhlbi.nih.gov/health/health-topics/topics/sdd/howmuch

23. Touitou Y, Reinberg A, Touitou D (2017) Association between light at night, melatonin secretion, sleep deprivation, and the internal clock: health impacts and mechanisms of circadian disruption. Life Sci 173:94-106. https://doi.org/10.1016/j.lfs.2017.02.008

24. VanderLaan WP, Parker DC, Rossman LG, VanderLaan EF (1970) Implications of growth hormone release in sleep. Metabolism 19(10):891-897. https://doi.org/10.1016/0026-0495(70)90086-7
25. Wright KP Jr, Drake AL, Frey DJ, Fleshner M, Desouza CA, Gronfier C, Czeisler CA (2015) Influence of sleep deprivation and circadian misalignment on cortisol, inflammatory markers, and cytokine balance. Brain Behav Immun 47:24-34. https://doi. org/10.1016/j.bbi.2015.01.004

26. Venancio DP, Suchecki D (2015) Prolonged REM sleep restriction induces metabolic syndrome-related changes: mediation by proinflammatory cytokines. Brain Behav Immun 47:109-117. https:// doi.org/10.1016/j.bbi.2014.12.002

27. Meier-Ewert HK, Ridker PM, Rifai N, Price N, Dinges DF, Mullington JM (2002) Effect of sleep loss on C-reactive protein, an inflammatory marker of cardiovascular risk. Sleep 25:A105-A105

28. Amstrup AK, Sikjaer T, Heickendorff L, Mosekilde L, Rejnmark L (2015) Melatonin improves bone mineral density at the femoral neck in postmenopausal women with osteopenia: a randomized controlled trial. J Pineal Res 59(2):221-229. https://doi.org/10.1111/jpi.12252

29. Ping Z, Wang Z, Shi J, Wang L, Guo X, Zhou W, Hu X, Wu X, Liu Y, Zhang W, Yang H, Xu Y, Gu Y, Geng D (2017) Inhibitory effects of melatonin on titanium particle-induced inflammatory bone resorption and osteoclastogenesis via suppression of NFkappaB signaling. Acta Biomater 62:362-371. https://doi.org/10. 1016/j.actbio.2017.08.046

30. Krantz E, Trimpou P, Landin-Wilhelmsen K (2015) Effect of growth hormone treatment on fractures and quality of life in postmenopausal osteoporosis: a 10-year follow-up study. J Clin Endocrinol Metab 100(9):3251-3259. https://doi.org/10.1210/jc.2015-1757

31. Tritos NA (2017) Focus on growth hormone deficiency and bone in adults. Best Pract Res Clin Endocrinol Metab 31(1):49-57. https:// doi.org/10.1016/j.beem.2017.02.002

32. Carcamo-Orive I, Gaztelumendi A, Delgado J, Tejados N, Dorronsoro A, Fernandez-Rueda J, Pennington DJ, Trigueros C (2010) Regulation of human bone marrow stromal cell proliferation and differentiation capacity by glucocorticoid receptor and AP-1 crosstalk. J Bone Miner Res 25(10):2115-2125. https://doi.org/10.1002/jbmr.120

33. Hardy RS, Zhou H, Seibel MJ, Cooper MS (2018) Glucocorticoids and bone: consequences of endogenous and exogenous excess and replacement therapy. Endocr Rev 39(5):519-548. https://doi.org/ 10.1210/er.2018-00097

34. Xiao W, Wang Y, Pacios S, Li S, Graves DT (2016) Cellular and molecular aspects of bone remodeling. Front Oral Biol 18:9-16. https://doi.org/10.1159/000351895

35. Miller MA, Cappuccio FP (2007) Inflammation, sleep, obesity and cardiovascular disease. Curr Vasc Pharmacol 5(2):93-102. https:// doi.org/10.2174/157016107780368280

36. Stone KL, Ewing SK, Lui LY, Ensrud KE, Ancoli-Israel S, Bauer DC, Cauley JA, Hillier TA, Cummings SR (2006) Self-reported sleep and nap habits and risk of falls and fractures in older women: the study of osteoporotic fractures. J Am Geriatr Soc 54(8):11771183. https://doi.org/10.1111/j.1532-5415.2006.00818.x

37. Chen G, Chen L, Wen JP, Yao J, Li LT, Lin LX, Tang KK, Huang HB, Liang JX, Lin W, Chen HJ, Li MZ, Gong XY, Peng SS, Lu JL, Bi YF, Ning G (2014) Associations between sleep duration, daytime nap duration, and osteoporosis vary by sex, menopause, and sleep quality. J Clin Endocr Metab 99(8):2869-2877. https://doi.org/10.1210/jc.2013-3629

38. Burch JB, Yost MG, Johnson W, Allen E (2005) Melatonin, sleep, and shift work adaptation. J Occup Environ Med 47(9):893-901. https://doi.org/10.1097/01.jom.0000177336.21147.9f

39. Bracci M, Copertaro A, Manzella N, Staffolani S, Strafella E, Nocchi L, Barbaresi M, Copertaro B, Rapisarda V, Valentino M, Santarelli L (2013) Influence of night-shift and napping at work on urinary melatonin, $17-\beta$-estradiol and clock gene expression in premenopausal nurses. J Biol Regul Homeost Agents 27(1):267-274

Publisher's note Springer Nature remains neutral with regard to jurisdictional claims in published maps and institutional affiliations. 